\title{
Statistical Study on Malignant Melanoma in Japan (1970-1976)
}

\author{
Takeshi Ohsumi and Makoto Seiji
}

Department of Dermatology, Iwaki Hyoritsu Hospital, Iwaki, and Department of Dermatology, Tohoku University School of Medicine, Sendai

\begin{abstract}
Orstrir, T, and Seru, M. Statistical Study on Malignant Melanoma in Japan (1970-1976). Tohoku J. exp. Med., 1977, 121 (4), 355-364_The authors reported in 1972 a statistical study based on 501 cases of malignant melanoma. As continuous study this review was carried out on 456 cases of melanoma which were reported during six years between 1970 and 1976 . These two studies showed quite similar results as follows: (1) Yearly incidence of malignant melanoma indicated a definite upward trend and the average number of patients was 71.1 per year. (2) Distribution by age showed one peak in the seventh decade. (3) Sex ratio was 1.1: 1. (4) The number of cases per total population in Japan showed great increase in over fifth decades and two peaks in the 7th and 8th decades. (5) Average age of the onset of all melanoma was 51.6 years old, while, that of brain and spinal cord melanoma was 25.4 years old. In the skin melanoma with preexisting pigmented skin lesions, the median age of the onset of primary melanoma on the foot was 38.7 years old and that of originated melanoma except foot was 65.9 years old. (6) Incidence of the melanoma was high in the sole considering the number of melanocytes per unit skin area.

Metastasis of eye melanoma was low $(23 \%)$. melanoma
\end{abstract}

In 1972, the authors reported on "Statistical Study on Malignant Melanoma in Japan (1961-1970)". As continuous study this statistical study on 456 cases of malignant melanoma reported in Japan during the last 6 years from 1970 to 1976 was carried out. The incidence of malignant melanoma among Japanese has been thought to be significantly low as compared with that of Caucasians. It was reported that the racial ratio between Caucasians and other races was 250:1. In our country, however, the incidence of malignant melanoma indicates a definite upward trend in recent years. There is no difference in the number of melanocytes per unit area of the particular skin area among white and black races, but the amount of melanin produced differs in races. Pigment cells from which malignant melanoma derives are seen in skin or mucous basal cell layer, dermis, hair follicles, meninges encephali or chorioides. There seemed to be a parallel relationship between the incidence of melanoma and the number of melanocytes in the particular skin area except on the sole where an incidence of melanoma was exceptionally high on the bases of the number of melanocytes per unit skin area.

Malignant melanoma has been classified in many ways according to their

Received for publication, November 9, 1976. 
clinical and/or pathological characteristics. Recently, however, it was classified into the following major three groups by Mihm et al. (1971); (1) lentigo maligna type, (2) superficial spreading type, (3) nodular type, and (4) undeterminate type. All forms differ in their mode of onset, course and prognosis, and each has distinctive clinical and histopathological appearances. So, statistical studies on each individual type of malignant melanoma will be carried out in future according to this classification.

\section{Materials}

As a follow-up study, the statistical work was carried out on all cases of malignant melanoma reported in the Japan Centra Revuo Medicina, which is a journal abstract covering almost all medical journals published in Japan. This particular statistical review was made of each original journal, quoted Japan Centra Revuo Medicina from March 1970 through July 1976 , between volumes 255 and 322 . All of 456 cases seemed to have occurred in Japanese because of no case of foreigner. Occasionally a particular case was reported independently in the different journals and in this study such overlapped cases were seen over 110 cases. In order to carry out the more precise study we tried as much as possible to eliminate these overlapped cases by checking up the individual original journals in which the cases were reported.

\section{Results AND Discussion}

\section{Numbers of malignant melanoma between 1961 and 1976}

The histogram (Fig. 1) shows the yearly incidence of melanoma between 1961 and 1976. White columns indicate the number of melanoma collected in the previous report (Seiji and Ohsumi 1972) and zebra columns the number of this report. In the previous statistics, the yearly incidence of melanoma revealed a definite upward trend every year up to 1967. However, as Fig. 1 shows, there was one peak in 1967, and after 1969 it was within a limited range. The abnormal

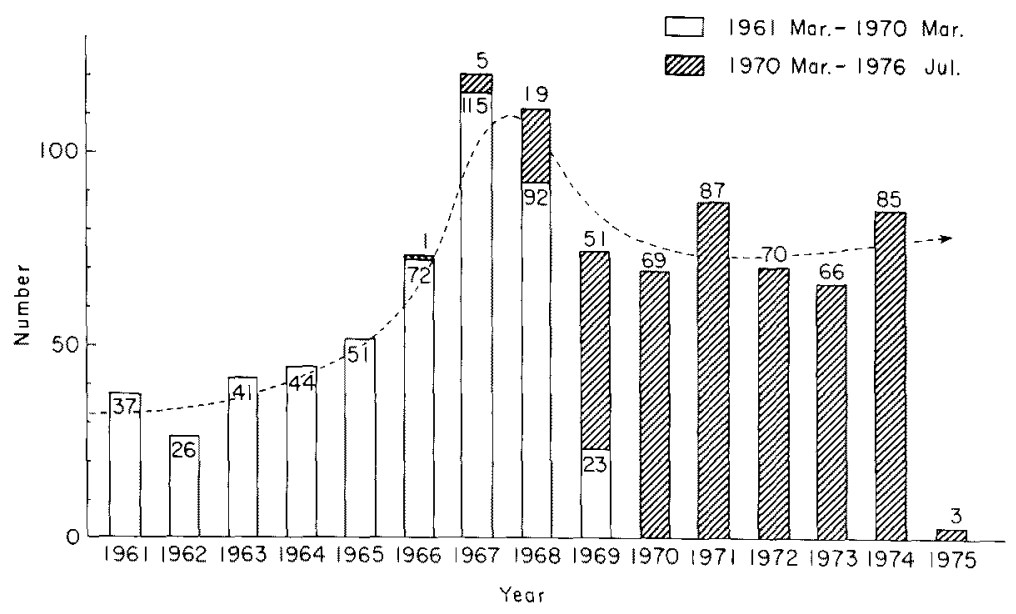

Fig. 1. Yearly incidence of malignant melanoma. 1961 Mar. 1976 July. 
upward trend seen between 1965 and 1967 may indicate that a great interest was focused on malignant melanoma in these years because the new, stimulative clinico-pathological studies were being carried out on malignant melanoma during those years in the U.S.A. and Australia. After 1975 there seems to show a slight upward trend ranging between 70 and 90 cases per year. This review study deals only with the reported cases in Japan Centra Revuo Medicina so that the cases were recorded on the reported year, but in order to analyze the yearly incidence it would be much better to count the year of an onset of the melanoma instead of recording the year when the cases were reported. Unfortunately it was almost impossible to do so because of the nature of this kind of journal.

\section{Age and sex distribution}

Fig. 2 gives the sex and age distribution of 456 cases. White columns indicate the numbers of male and zebra ones those of female. In the previous report there were two peaks in the fifth and seventh decades in male and one peak in the seventh decade in female. However, this figure shows only one peak in the seventh decade in both male and female.

Fig. 3 presents a comparison of the incidence of malignant melanoma by sex in three statistical studies which reported by Yoshida in 1955, Kukita et al. in 1961 and Seiji and Ohsumi in 1972 and the present study. The sex ratio of our 957 cases was 1.1:1 and the ratio of four reports was $1.27: 1$. The incidence of melanoma seems to be slightly higher in the male group than in the female. The sex ratio of obduction in Japan is reported to be 10:7, and it may be concluded that the mortality of female is low or the number of female obduction small. The average incidence per year shows a great increase in the latest group among these four generations and the latest average per year of 456 cases shows 71.1 cases per year.

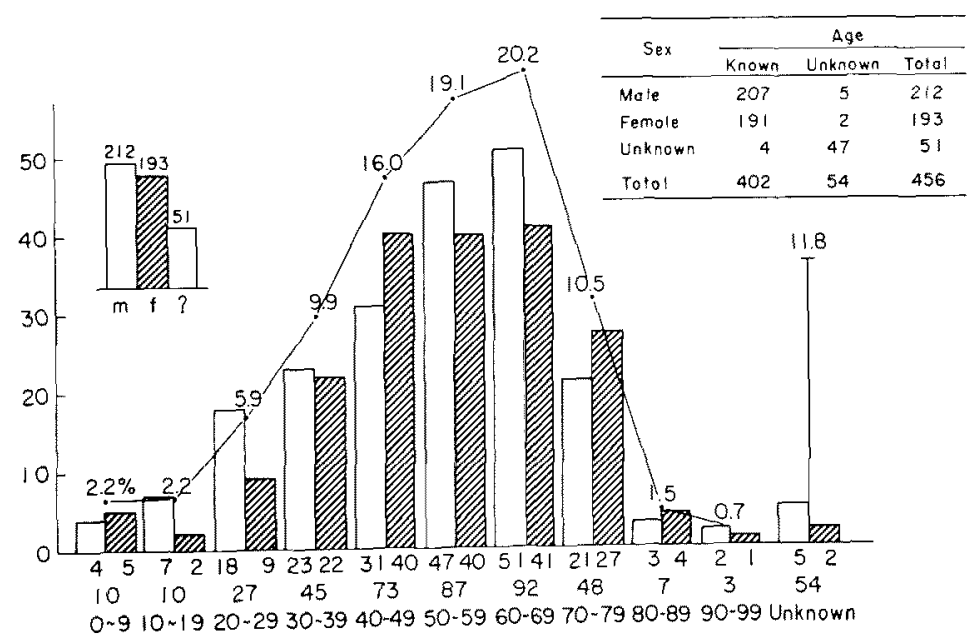

Fig. 2. Distribution of 456 cases of malignant melanoma according to age and sex. 1970 Mar. 1976 July. 


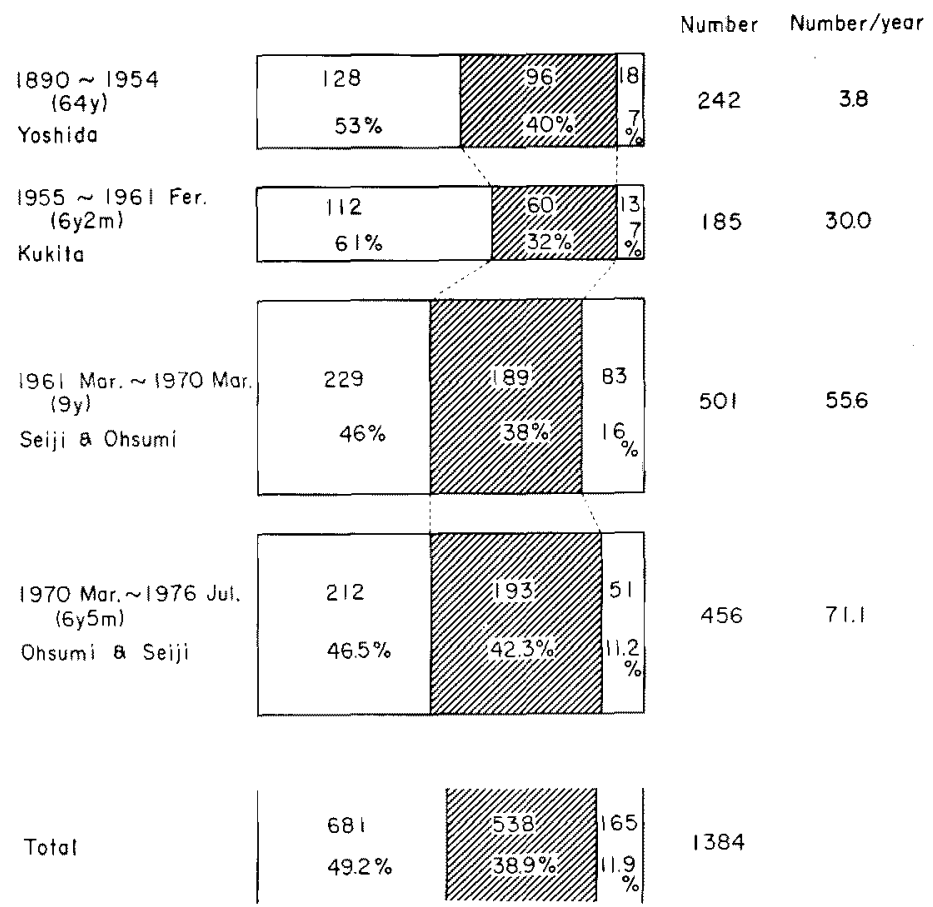

Fig. 3. Comparison of the incidence of malignant melanoma by sex among the four statistical studies.

Table 1 presents a relationship between the age distribution of malignant melanoma and of population and shows a relationship between the incidence of melanoma by age per ten thousand of population in Japan in 1971. And this table indicates a great increase over the fifth decade and there appears to be two peaks in the seventh and eighth decades.

\section{Location}

Table 2 elucidates the locations of the primary lesion by sex during 1961 March and 1976 July and Table 3, during 1970 March and 1976 July. There are a few differences in these two tables. In the sex ratio, genital organ and anorectum are

TABLE 1. Relationship between the age distribution of malignant

\begin{tabular}{|c|c|c|c|c|}
\hline & & $0-9$ & $10-19$ & $20-29$ \\
\hline (1) & Number of malignant melanomas & 10 & 10 & 27 \\
\hline (2) & Number of malignant melanomas per year & 1.77 & 1. 77 & 4. 77 \\
\hline (3) & Japanese population in $1971^{*}$ & $174 \times 10^{5}$ & 164 & 198 \\
\hline \multirow{2}{*}{ (4) } & Malignant melanomas $\quad(2)$ & \multirow[b]{2}{*}{0.010} & \multirow[b]{2}{*}{0.011} & \multirow[b]{2}{*}{0.024} \\
\hline & $100,000=\frac{13}{(3)} \times 10^{5}$ & & & \\
\hline
\end{tabular}

\footnotetext{
* Kosei no Shihyo (Jap.), edited by Kishi, T., Kosei Tokei Kyokai, Tokyo, 1968-1975,
} 
TABLE 2. Incidence in location of the primary lesions and the sex ratio (1961 Mar. $1976 \mathrm{Jul}$.)

\begin{tabular}{|c|c|c|c|c|c|}
\hline Location & $\begin{array}{c}\text { Number of } \\
\text { patients }\end{array}$ & $\%$ & Male & Female & Unknown \\
\hline Skin & 313 & 32.7 & 171 & 122 & 20 \\
\hline scalp, face or neck & 49 & 5. 1 & 22 & 24 & 3 \\
\hline trunk & 68 & 7.1 & 40 & 22 & 6 \\
\hline upper extremity & 43 & 4.5 & 20 & 23 & - \\
\hline lower extremity & 147 & 15.4 & 84 & 52 & 11 \\
\hline unknown & 6 & 0.6 & 5 & 1 & 一 \\
\hline Mucosa & 259 & 27.1 & 95 & 114 & 50 \\
\hline nose & 84 & 8.8 & 38 & 30 & 16 \\
\hline mouth & 134 & 14.0 & 48 & 53 & 33 \\
\hline pharynx & 4 & 0.4 & 1 & 2 & 1 \\
\hline genital organ & 37 & 3.9 & 8 & 29 & 一 \\
\hline Others & 332 & $\mathbf{3 4 . 7}$ & 154 & 132 & 46 \\
\hline brain or spinal cord & 58 & 6.1 & 30 & 15 & 13 \\
\hline eye & 205 & 21.4 & 94 & 78 & 33 \\
\hline gastrointestinal traet & 65 & 6.8 & 27 & 38 & 一 \\
\hline lung & 4 & 0.4 & 3 & 1 & - \\
\hline Unknown & 53 & 5.5 & 21 & 14 & 18 \\
\hline Total & 957 & 100.0 & 441 & 382 & 134 \\
\hline
\end{tabular}

more frequent sites in female than male; on the other hand, trunk and lower extremity in male. According to the statistical study on obduction in the last 10 years (Mori 1971), the most frequent site of involvement was skin and the least was eye. This low incidence of the eye melanoma mortality may be due to the following reasons; usually they will be found in the early stage and treated immediately, in most cases radically such as extraction of the eye bulb. Among the eye melanoma, chorioides is the most common site of involvement, that is, 107 out of 205 cases reported during 1961 March and 1976 July. Shinbo et al. (1970) reported that $80 \%$ of the primary melanomas of eye were chorioides melanomas.

Nasal and oral malignant melanoma is one of the most common melanomas in Japan. As has been pointed out by Shimizu et al. (1972), the initial symptom of nasal melanoma may be epistaxis or nasal obstruction, and nasal melanomas have often been reported too. Among oral melanoma, palate melanoma was 20 cases

\begin{tabular}{|c|c|c|c|c|c|c|}
\hline \multicolumn{6}{|c|}{ Age } & \multirow{2}{*}{ Total } \\
\hline $30-39$ & $40-49$ & $50-59$ & $60-69$ & $70-79$ & 80 & \\
\hline 45 & 73 & 87 & 92 & 48 & 10 & 402 \\
\hline 8.00 & 12.9 & 15.4 & 16.3 & 8.49 & 1.77 & 71.1 \\
\hline 169 & 137 & 94 & 69 & 36 & 10 & $1050 \times 10^{5}$ \\
\hline 0.047 & 0.094 & 0.16 & 0.24 & 0.24 & 0.18 & 0.0677 \\
\hline
\end{tabular}

15-22. 
TABLE 3. Incidence in location of the primary lesions and the sex ratio (1970 Mar. 1976 Jul.)

\begin{tabular}{lrrrrrrr}
\hline \multicolumn{1}{c}{ Location } & Number & $\%$ & Male & Female & ? & $\begin{array}{c}\text { Average of } \\
\text { age }\end{array}$ & Number \\
\hline Skin & $\mathbf{1 7 0}$ & $\mathbf{3 7 . 3}$ & $\mathbf{9 5}$ & $\mathbf{6 4}$ & $\mathbf{1 1}$ & $\mathbf{4 9 . 8}$ & $\mathbf{1 5 4}$ \\
scalp, face or neck & 20 & 4.4 & 12 & 8 & - & 39.1 & 20 \\
trunk & 37 & 8.1 & 20 & 13 & 4 & 39.8 & 33 \\
upper extremity & 24 & 5.3 & 10 & 14 & - & 49.9 & 22 \\
lower extremity & 83 & 18.2 & 48 & 28 & $\mathbf{7}$ & 56.8 & $\mathbf{7 8}$ \\
unknown & 6 & 1.3 & 5 & 1 & - & 41. & 1 \\
Mucosa & $\mathbf{1 2 4}$ & $\mathbf{2 7 . 2}$ & $\mathbf{4 5}$ & $\mathbf{6 2}$ & $\mathbf{1 7}$ & $\mathbf{5 6 . 5}$ & $\mathbf{1 0 8}$ \\
nose & 47 & 10.3 & 19 & 18 & 10 & 56.0 & 38 \\
mouth & 49 & 10.8 & 19 & 23 & $\mathbf{7}$ & 58.6 & $\mathbf{4 2}$ \\
pharynx & 2 & $0 . \mathbf{4}$ & 1 & 1 & - & 60.0 & $\mathbf{2}$ \\
genital organ & 26 & 5.7 & 6 & 20 & - & 53.7 & 26 \\
Others & $\mathbf{1 4 6}$ & $\mathbf{3 2 . 0}$ & $\mathbf{6 6}$ & $\mathbf{6 3}$ & $\mathbf{1 6}$ & $\mathbf{5 0 . 2}$ & $\mathbf{1 3 0}$ \\
brain or spinal cord & 21 & $\mathbf{4 . 6}$ & 12 & 4 & 5 & 25.4 & 17 \\
eye & 85 & $\mathbf{1 8 . 6}$ & 33 & 40 & 12 & 50.5 & 73 \\
gastrointestinal tract & 37 & 8.1 & 18 & 19 & - & 60.2 & 37 \\
lung & 3 & 0.7 & 3 & - & - & 62.3 & 3 \\
Unknown & $\mathbf{1 6}$ & $\mathbf{3 . 5}$ & $\mathbf{6}$ & $\mathbf{4}$ & $\mathbf{6}$ & $\mathbf{4 4 . 7}$ & $\mathbf{1 0}$ \\
\multicolumn{1}{c}{ Total } & $\mathbf{4 5 6}$ & $\mathbf{1 0 0 . 0}$ & $\mathbf{2 1 2}$ & $\mathbf{1 9 3}$ & $\mathbf{5 1}$ & $\mathbf{5 1 . 6 2}$ & $\mathbf{4 0 2}$ \\
\hline
\end{tabular}

out of 49 cases and gingiva or alveolar 19 cases. As Chaudhry et al. (1958) pointed out, frequent sites were hard palate, gingiva and soft palate and lower jaw was uncommon site. Oral melanoma with preexisting pigmentation was seen frequently. Out of 94 cases, Takagi et al. (1972) reported 34 cases of oral melanoma with preexisting pigmentation and secondary pigmentation was observed in 28 cases. Table 2 presents the average age of 402 cases.

In the previous report, the incidences of brain and spinal cord melanoma by age showed a peak in the third decade. In this paper, 21 cases (male 12, female 4, unknown 5) were described and the median age was 25.4 years old and the age distribution was as follows:

\begin{tabular}{l|cccccccc|c} 
Age & $0-9$ & $10-19$ & $20-29$ & $30-39$ & $40-49$ & $50-59$ & $60-$ & Unknown & Total \\
\hline Number & 4 & 1 & 6 & 3 & - & 3 & - & 4 & 21
\end{tabular}

Gibson et al. (1957) reported that the 4th decade was most frequent in the Western countries. Takeda et al. (1974) reported that the diffuse black pigmentation was seen in meninges encephali in 42 out of 43 cases in Japan, and in 14 cases among them a deposit was observed in hemisphaerium.

The average age of trunk and face melanomas was 39.5 years old and this was low next to that of brain and spinal cord melanomas.

Table 4 shows the locations of the primary lesions of the lower extremity. The most frequent site of involvement was sole.

The relationship between the onset of melanoma and the distribution of melanocytes in the skin of the different parts of the body is shown in Table 5. As 
TABLE 4. Incidence in location of the primary lesions of lower extremity (1961 Mar. $1976 \mathrm{Jul}$.)

\begin{tabular}{lrrrrc}
\hline \multicolumn{1}{c}{ Location } & Number & $\%$ & Male & Female & Unknown \\
\hline Thigh & $16(7)$ & 10.9 & 7 & 6 & 3 \\
Knee & $5(2)$ & 3.4 & 1 & 3 & 1 \\
Leg & $17(11)$ & 11.5 & 10 & 7 & - \\
Back of foot & $6(5)$ & 4.1 & 4 & 2 & - \\
Toe & $27(15)$ & 18.4 & 16 & 7 & 4 \\
Sole & $75(43)$ & 51.0 & 46 & 26 & 3 \\
Unknown & $1(-)$ & 0.7 & - & 1 & - \\
$\quad$ Total & $147(83)$ & 100.0 & 84 & 52 & 11 \\
\hline
\end{tabular}

TABLE 5. Relationship between the site distribution of malignant melanoma and the number of melanocytes per unit skin area in patients over 15 years old (1961 Mar. 1976 Jul.)

\begin{tabular}{lcccccc}
\hline Site & $\begin{array}{c}(1) \\
\text { Number of } \\
\text { patients }\end{array}$ & $\begin{array}{c}(2) \\
\text { Percentage } \\
\text { of (1) }\end{array}$ & $\begin{array}{c}\text { Proportion of skin } \\
\text { area in different } \\
\text { parts of the body }\end{array}$ & $(2) /(3)$ & $\begin{array}{c}\text { Number of } \\
\text { melanocytes } \\
\text { per mm }\end{array}$ \\
\hline Scalp, face \& neck & $48(19)$ & $16.4 \%$ & $10.0 \%$ & 1.64 & $1400-1930$ \\
Arm & $12(5)$ & 4.1 & 14.3 & 0.29 & 1160 \\
Hand & $27(16)$ & 9.3 & 5.1 & 1.81 & 1120 \\
Trunk & $57(29)$ & 19.5 & 23.7 & 0.82 & 890 \\
Genital organ (5) & $7(5)$ & 2.4 & 0.5 & 4.79 & $2100-2380$ \\
Thigh, knee \& leg & $36(17)$ & 12.3 & 39.6 & 0.32 & 1130 \\
Foot (except sole) & $33(20)$ & 11.3 & 4.0 & 2.83 & $1420-2840$ \\
Sole & $72(40)$ & 24.7 & 2.8 & 8.81 & 1680 \\
\multicolumn{1}{c}{ Total } & $292(151)$ & $100.0 \%$ & $100.0 \%$ & & \\
\hline
\end{tabular}

( ); 1970 Mar.-1976 Jul.

has been reported, melanoma occurred predominantly on the sole. It was reported that $86 \%$ of the skin melanomas were found on lower limbs in the East and Central Africa and almost of these were seen on the sole and $30 \%$ of the skin melanomas occurred on lower limbs among Caucasians. While the incidence of melanoma of lower extremity in Japanese was $45 \%$ among 313 cases of skin melanoma and $51 \%$ of the disease on lower extremity were seen in sole; therefore, the type of melanoma in Japanese may be different from that in African's.

\section{Metastasis}

Table 6 gives the incidence of metastasis of malignant melanoma by sex and age, and Table 7 gives the frequency of metastasis by site primarily affected during 1961 March and 1976 July. Age distribution pattern was similar to that of the previous report. The site distribution pattern also showed similar tendency, and a high incidence (over $60 \%$ ) of metastasis was recognized in the melanomas affected primarily on the trunk, lower limbs and gastrointestinal tract, while the lower frequency of metastasis was observed in cases of eye melanoma (23\%) (Table 7). 
TABLE 6. Incidence of metastasis of malignant melanoma

\begin{tabular}{llrrrr}
\hline \multirow{2}{*}{ Sex } & & & & & \\
\cline { 3 - 6 } Male & & $0-9$ & $10-19$ & $20-29$ & $30-39$ \\
\cline { 3 - 6 } Female & metastasis (+) & 2 & 4 & 6 & 14 \\
\multirow{4}{*}{ Unknown } & meta. (-) or (?) & 2 & 3 & 12 & 9 \\
& metastasis (+) & 3 & 1 & 4 & 11 \\
& meta. (-) or (?) & 2 & 1 & 5 & 11 \\
& metastasis (+) & 1 & - & - & - \\
& meta. (-) or (?) & - & 1 & - & - \\
& metastasis (+) & 6 & 5 & 10 & 25 \\
& meta. (-) or (?) & 4 & 5 & 17 & 20 \\
& Total & 10 & 10 & 27 & 45 \\
\hline
\end{tabular}

TABLE 7. Incidence of metastasis of malignant melanoma by site primarily affected (1961 Mar. 1976 Jul.)

\begin{tabular}{|c|c|c|c|}
\hline \multirow{2}{*}{ Location } & Metastasis $(+)$ & \multirow{2}{*}{ Meta. $(-),(?)$} & \multirow{2}{*}{ Total } \\
\hline & Number $(\%)$ & & \\
\hline & $184(59)$ & 129 & 313 \\
\hline scalp, face or neck & $24(49)$ & 25 & 49 \\
\hline trunk & $45(66)$ & 23 & 68 \\
\hline upper extremity & $25(58)$ & 18 & 43 \\
\hline lower extremity & $84(57)$ & 63 & 147 \\
\hline unknown & $6(100)$ & - & 6 \\
\hline Mucosa & $121(47)$ & 138 & 259 \\
\hline nose & $42(50)$ & 42 & 84 \\
\hline mouth & $62(46)$ & 72 & 134 \\
\hline pharynx & $1(25)$ & 3 & 4 \\
\hline genital organ & $16(43)$ & 21 & 37 \\
\hline Others & $112(34)$ & 220 & 332 \\
\hline brain or spinal cord & $16(28)$ & 42 & 58 \\
\hline & $48(23)$ & 157 & 205 \\
\hline gastrointestinal tract & $45(69)$ & 20 & 65 \\
\hline lung & $3(75)$ & 1 & 4 \\
\hline Unknown & $33(62)$ & 20 & 53 \\
\hline Total & $450(47.0)$ & 507 & 957 \\
\hline
\end{tabular}

This might be due to the fact that the radical treatment, mostly eye extraction, was performed in the early stage. The average period between the eye extraction and the metastasis was reported to be 46 months.

Age distribution of skin malignant melanoma with preexisting pigmented skin lesions

Table 8 shows the age distribution of 154 cases of skin malignant melanoma with and without preexisting pigmented skin lesions. The average age of foot melanoma with preexisting pigmented skin lesions was 65.9 years old, which was considered to be significantly higher compared with the median age of 402 cases of 
by sex and age (1970 Mar. 1976 Jul.)

\begin{tabular}{cccccccc}
\hline Age & & & & & & \\
\cline { 1 - 5 } $40-49$ & $50-59$ & $60-69$ & $70-79$ & $80-89$ & $90-99$ & Unknown & Total \\
\cline { 1 - 5 } 20 & 22 & 31 & 13 & 1 & - & 4 & 117 \\
11 & 25 & 20 & 8 & 2 & 2 & 1 & 95 \\
17 & 19 & 24 & 14 & - & 1 & 1 & 95 \\
23 & 21 & 17 & 13 & 4 & - & 1 & 98 \\
2 & - & - & - & - & - & 11 & 14 \\
- & - & - & - & - & - & 36 & 37 \\
39 & 41 & 55 & 27 & 1 & 1 & 16 & $226(49.6 \%)$ \\
34 & 46 & 37 & 21 & 6 & 2 & 38 & $230(50.4 \%)$ \\
73 & 87 & 92 & 48 & 7 & 3 & 54 & 456 \\
\hline
\end{tabular}

TABLE 8. Age distribution of skin malignant melanoma with preexisting pigmented skin lesions (1970 Mar. 1976 Jul.)

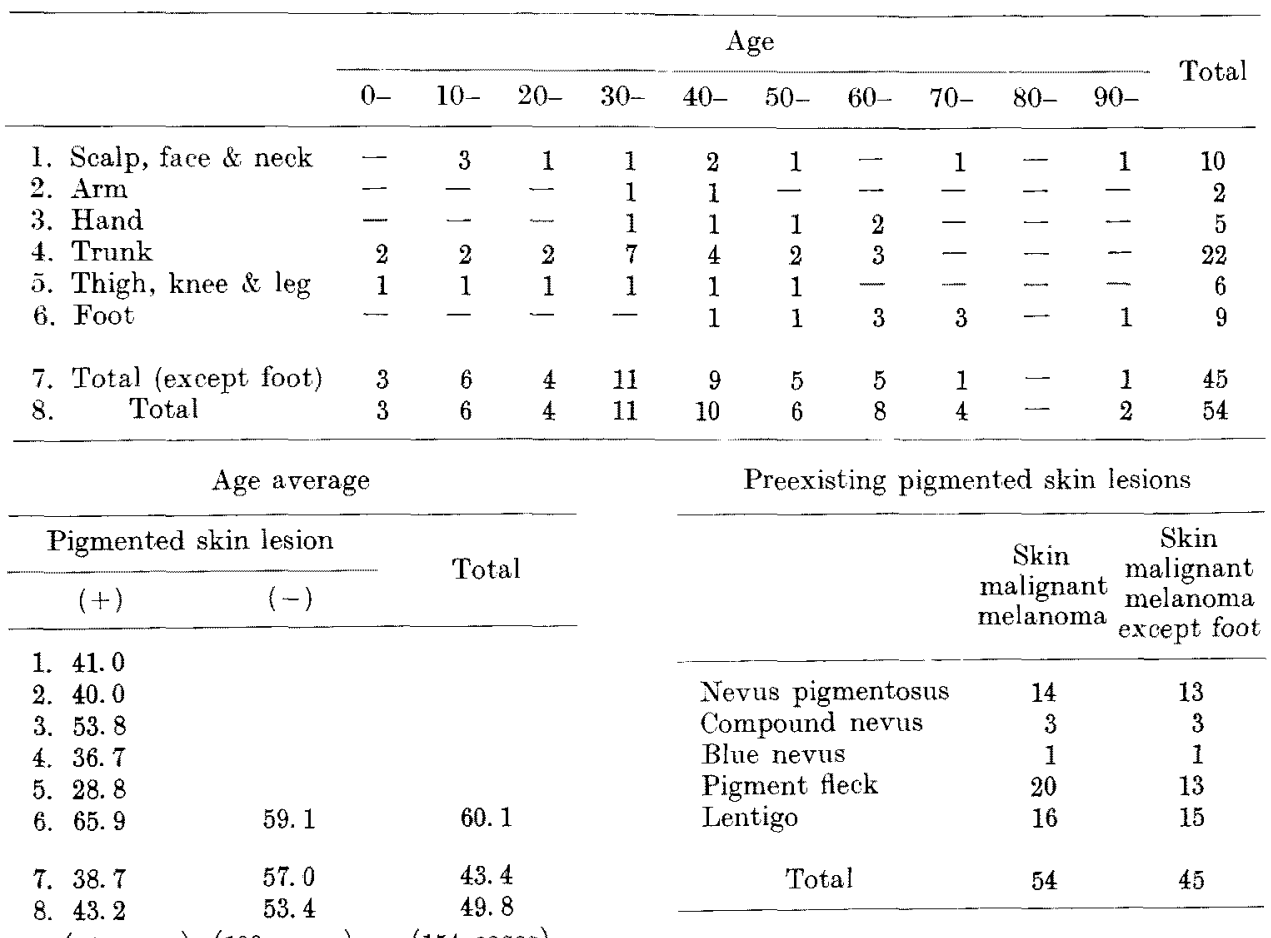

(54 cases) (100 cases) (154 cases)

all melanoma collected. However, that of skin melanoma with preexisting pigmented skin lesions except foot was 38.7 years old. In other words, among the skin melanoma with preexisting pigmented skin lesions, the foot melanoma was more severe in older age; on the other hand, the skin melanoma except foot appeared in much younger generation. The designations of the pigmented skin 
lesions were exactly listed up in Table 8 as they were described in the original reports. Most of these pigmented skin lesions were reported to have existed for more than five years.

\section{References}

1) Chaudhry, A.P., Hampel, A. \& Gorlin, R.T. (1958) Primary malignant melanoma of the oral cavity; a review of 105 cases. Cancer, 11, 923-928.

2) Gibson, J.B., Burrows, D. \& Weir, W.P. (1957) Primary melanoma of the meninges. J. Path. Bact., 74, 419-438.

3) Japan Centra Revuo Medicina, edited by F. Amako \& S. Matsumoto, Igaku Chuozasshi Kankokai, Tokyo, 1970-1976, 255-322.

4) Kukita, A., Ueno, K., Ikeda, S., Mori, S. \& Ito, H. (1961) Clinic for malignant melanoma. Hifuka no Rinsho (Jap.), 3, 519-528.

5) Mihm, M.C., Clark, W.H. \& From, L. (1971) Clinical diagnosis, classification and histogenetic concepts of the early stages of cutaneous malignant melanomas. New Engl. J. Med., 284, 1078-1082.

6) Mori, W. (1971) Malignant melanoma in Japan. Gan no Rinsho (Jap.), 17, 245-246.

7) Seiji, M. \& Ohsumi, T. (1972) Statistical study on malignant melanoma in Japan (1961-1970). Tohoku J. exp. Med., 107, 115-125.

8) Shimizu, Y., Kumoi, T., Hattori, H., Fujitani, T., Fukuzumi, H., Mori, M. \& Asai, R. (1972) 12 cases of nasal and oral melanoma. Nihon Jibi-Inkoka (Jap.), 75, 1120-1121.

9) Shinbo, N., Sugamata, H. \& Daita, T. (1970) A case of ciliar body malignant melanoma. Ganka Rinsho Tho (Jap.), 64, 32-36.

10) Takagi, M., Ishikawa, G. \& Horiuchi, J. (1972) Characteristic oral melanoses associated with primary malignant melanoma of the oral cavity. Kokubyo Gakkaizasshi (Jap.), 39, 565-577.

11) Takeda, F., Kohno, N., Kumagai, N., Aiba, T., Kawafuchi, J. \& Joshita, T. (1974) Primary malignant melanoma of the central nervous system associated with neurocutaneous melanosis. Shinkei Shinpo (Jap.), 18, 603-614.

12) Yoshida, Y. (1955) Malignant melanoma in Japan. Indian J. Derm. Venereol., 21, $59-64$. 